\title{
The Vulnerable Subject: Anchoring Equality in the Human Condition
}

\author{
Martha Albertson Fineman ${ }^{\dagger}$
}

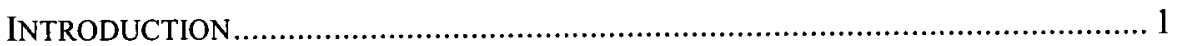

I. THE LIMITS OF FORMAL EQUALITY ................................................ 2

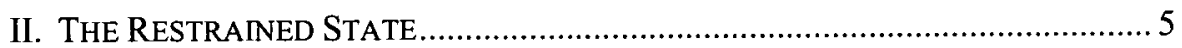

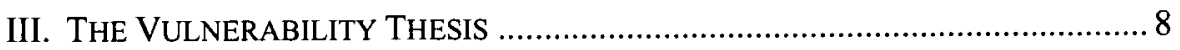

A. The Vulnerable Subject .................................................... 10

B. The Vulnerable Society and Its Institutions .............................. 12

IV. ASSESSING AND ADDRESSING PRIVILEGE AND DISADVANTAGE............... 15

V. THE RESPONSIVE STATE ............................................................... 19

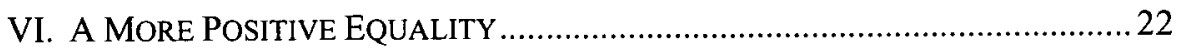

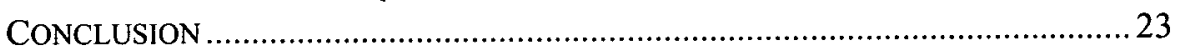

\section{INTRODUCTION}

In this essay I develop the concept of vulnerability in order to argue for a more responsive state and a more egalitarian society. I argue that vulnerability is-and should be understood to be-universal and constant, inherent in the human condition. The vulnerability approach I propose is an alternative to traditional equal protection analysis; it is a "post-identity" inquiry in that it is not focused only on discrimination against defined groups, but concerned with privilege and favor conferred on limited segments of the population by the state and broader society through their institutions. As such, vulnerability analysis concentrates on the structures our society has and will establish to manage our common vulnerabilities. This approach has the potential to move us beyond the stifling confines of current discrimination-based models toward a more substantive vision of equality.

To richly theorize a concept of vulnerability is to develop a more complex subject around which to build social policy and law; this new complex subject

\footnotetext{
$\dagger$ Robert W. Woodruff Professor of Law, Emory University; Director of the Feminism and Legal Theory Project. I would like to thank Sara Elizabeth Apel and Adam P. Romero for their valuable assistance on this essay and their words of encouragement when deadlines loomed. I am also grateful to Yale Journal of Law and Feminism editors Emily Chapuis and Amanda Shanor for their excellent editorial suggestions.
} 
can be used to redefine and expand current ideas about state responsibility toward individuals and institutions. In fact, I argue that the "vulnerable subject" must replace the autonomous and independent subject asserted in the liberal tradition. Far more representative of actual lived experience and the human condition, the vulnerable subject should be at the center of our political and theoretical endeavors. The vision of the state that would emerge in such an engagement would be both more responsive to and responsible for the vulnerable subject, a reimagining that is essential if we are to attain a more equal society than currently exists in the United States.

Before further developing the vulnerability thesis, I want to address some conceptual impediments to the idea of a more responsive state. First, an impoverished sense of equality is embedded in our current legal doctrine. We understand equality in terms that are formal, focused on discrimination, and inattentive to underlying societal inequities. Second, the view that the proper role of the state is one of restraint and abstention is politically powerful. Even self-identified progressive social reformers are suspicious of the state; the rhetoric of non-intervention prevails in policy discussions, deterring positive measures designed to address inequalities. Further, we idealize contract and correspondingly reify individual choice in ways that mask society's role in perpetuating inequality. The fact that societal institutions play a significant role in maintaining and extending inequality is the very reason that we need a more active state, one that is responsive to that reality.

\section{THE LIMITS OF FORMAL EQUALITY}

For centuries, the concept of "equality" in Western thought has been associated with John Locke's philosophy of liberal individualism (and the creation of the liberal subject). " "Equality" in the liberal model is the expression of the idea that all human beings are by nature free and endowed with the same inalienable rights. Although this vision of equality has inherent radical potential, in the United States today we have come to understand "equality" narrowly as the requirement of sameness of treatment, ${ }^{2}$ a formal anti-discrimination mandate primarily enforced through the courts. We all know the litany of protected categories found in the equal protection doctrine: race, sex, religion, national origin, and so on. ${ }^{3}$ These classifications define

1. See generally JOHN LOCKE, Two TREATISES OF GOVERnMENT (Ian Shapiro, ed., Yale Univ. Press 2003) (1689).

2. Martha albertson fineman, The Illusion of EQuality 46 (1991) [hereinafter The ILlUSION OF EQUALITY]; see also MARTHA ALBERTSON FINEMAN, THE AUTONOMY MYTH: A THEORY OF DEPENDENCY 10 (2004) [hereinafter THE AUTONOMY MYTH] ("Equality is manifested in mere formal or legal guarantees of sameness of treatment for individuals.").

3. Interestingly, in this catalogue, as well as in the law, class is absent as a suspect classification. See San Antonio Indep. Sch. Dist. v. Rodriguez, 411 U.S. 1 (1973) (rejecting the application of strict scrutiny to an education policy allegedly discriminating against students on the basis of class). Class bias 
individual legal identities and form the main axes around which claims for equal protection can be made. This system of identity categories defines the organization of interest groups. Indeed, these categories ultimately frame the content and influence the direction of American law.

Our current understanding of equality has been shaped in part by the twentieth-century history of the use of the equal protection doctrine as a tool to fight blatant forms of discrimination focused on race, sex, and ethnicity. In particular, feminist legal reformers during the latter part of the century were suspicious of any difference in treatment, even if it was designed to favor women. They demanded formal equality and rejected any "special" consideration because, in their experience, any classification based on asserted gender differences led to exclusion and subordination.

The problem with a formal model of equality is that it is limited in several important ways. Indeed, "equality," reduced to sameness of treatment or a prohibition on discrimination, has proven an inadequate tool to resist or upset persistent forms of subordination and domination. ${ }^{4}$ While this model might be used to successfully address some situations of discrimination, it fails to protect against others. Nor does our equal protection doctrine provide much protection against discrimination on the basis of categories not recognized as receiving heightened judicial scrutiny, such as disability and sexual orientation.

This version of equality is similarly weak in its ability to address and correct the disparities in economic and social wellbeing among various groups in our society. Formal equality leaves undisturbed - and may even serve to validate-existing institutional arrangements that privilege some and disadvantage others. It does not provide a framework for challenging existing allocations of resources and power. ${ }^{5}$ Unless some distortion is perceived to be introduced by impermissible bias, the state is not accountable. Nor is the state understood to appropriately intervene or interfere with the discrimination of private actors, be they in the "free" market or the "private" family. The formal equality model therefore not only fails to take into account existing inequality of circumstances, it also fails to disrupt persistent forms of inequality.

If we look at American society we see a long and growing list of material and social inequalities; we have no guarantee of basic social goods such as food, housing, and health care, and we have a network of dominant economic and political systems that not only tolerate, but justify grossly unequal

would bring economic arrangements into question and, for that reason, would be incompatible with a formal equality analysis that ignores disparate underlying circumstances, including economic inequality.

4. See, e.g., FINEMAN, THE IlLUSION OF EQUALITY, supra note 2, at 46, 174 (describing how sameness of treatment has failed to provide equality for women in the context of divorce).

5. Id. at 36-37 (analyzing the economic and social inequalities that persist despite the use of the formal equality model). 
distributions of wealth, power, and opportunity. ${ }^{6}$ Nevertheless, the sameness of treatment version of equality has proven resilient in the face of arguments for a more substantive concept of equality, one that is result-oriented and takes into account past circumstances and future obligations, considering need and disadvantage. What is more, sameness of treatment has been used to argue increasingly effectively against measures like affirmative action that might generate remedies for past inequities.

From a political and policy perspective, the current model of equality is further limited as an anti-discrimination principle because its protections do not appear to extend to everyone. Politically, this limitedness is problematic because it can and has resulted in significant backlash. Even more significant in the long run has been the fact that the goal of confronting discrimination against certain groups has largely eclipsed, even become a substitute for, the goal of eliminating material, social, and political inequalities that exist across groups. In this regard, identity categories are both over- and under-inclusive. ${ }^{7}$ The groups that traditional equal protection analyses recognize include some individuals who are relatively privileged notwithstanding their membership in these identity groups. Indeed, while race or gender may complicate and compound disadvantage, individual successes abound across these and other categories that the Equal Protection Clause demarcates. These individual successes create both theoretical and empirical pitfalls: Successful individuals who belong to a designated suspect class can undermine the coherence and dilute the strength of critical analyses based on asserted bias against the same identity group. At the same time, identity categories are too narrow. Poverty, denial of dignity, and deprivation of basic social goods are "lack-of-opportunity categories" that the current framework of identity groups does not recognize; such disadvantage transcends group boundaries.

The general tendency under a sameness of treatment equality framework is to focus on individuals and individual actions. The task under this approach is to identify the victims and the perpetrators of discrimination, as well as to define what were the prohibited activities, the individual injury, and the specific intent involved in each occurrence. Unless they are tied to individuals and discrimination, systemic aspects of existing societal arrangements are left out of the picture. It is as though existing material, cultural, and social imbalances are the product of natural forces and beyond the ability of the law to

6. See, e.g., John W. Lee III, Class Warfare 1988-2005 Over Top Individual Income Tax Rates: Teeter-Totter From Soak-The-Rich to Robin-Hood-In-Reverse, 2 HASTINGS BUS. L.J. 47, 147-49 (2006) (analyzing 2005 Census data documenting the growing rich/poor gap in American society).

7. I acknowledge that discrimination does exist, and I do recognize that these personal characteristics might work to complicate the experience of vulnerability for any individual. My claim is merely that discrimination models based on identity characteristics will not produce circumstances of greater equality and may in fact lead to less in many circumstances. For an example of this argument in the context of family law reform, see Chapter Three of FINEMAN, THE ILLUSION OF EQUALITY, supra note 2 . 
rectify. While it may be beyond the will of the law to alter, existing inequalities certainly are not natural. Inequalities are produced and reproduced by society and its institutions. Because neither inequalities nor the systems that produce them are inevitable, they can also be objects of reform.

\section{The Restrained StATE}

In American legal culture, the idea of the private acts as a principle of restraint and abstention. We accept the ideological assertion that it is appropriate to create barriers to keep the state out of our institutions and activities. This veneration of state non-intervention is a second major impediment to reforms intent on instituting a state that is more responsive to inequalities. $^{8}$

State restraint is often expressed in terms of the separate spheres ideology: there is a contrast between public and private domains, with the state cast as the quintessential public entity and the family cast as essentially private. ${ }^{9}$ Current conceptions of privacy are based on this dichotomy, which places some things and institutions presumptively beyond state regulation and control. The idea of family privacy "protects" the family and other intimate entities from state interference, while individual privacy shields certain intimate decisions from state control. ${ }^{10}$ Our economic institutions (such as the corporation) and our commercial practices (like those that govern wealth accumulation and distribution) are shielded by the black box of the free-market as it has been constructed in late American capitalism. ${ }^{11}$

Also contributing to a sense of inevitability when it comes to state restraint is the recently fashionable tendency to talk about the irrelevance-one could even say "withering away" —of the modern state. ${ }^{12}$ The suggestion is that one

8. To a great degree, our concept of the private also shields non-governmental actors from equality scrutiny. When deemed to be private actors, there is no state action to prompt constitutional scrutiny. See, e.g., Boy Scouts of America v. Dale, 530 U.S. 640 (2000) (affirming the Boy Scouts of America's First Amendment right to exclude homosexuals from membership in the organization and noting that no constitutional right or law providing public accommodation free from discrimination exists to contest such exclusionary policies). This aspect of the private versus public debate is beyond the scope of this essay, which focuses on state responsibility, particularly insofar as the state is responsible for the creation and maintenance of societal institutions. In this context, the state is an active player and there is no private action exemption.

9. The family is the quintessential private institution-private in its relationship with both market and state. On the other hand, while the market is cast as public vis-a-vis the family, it is private when paired with the state, a truly chameleon institution. Cf. lris Marion Young, Impartiality and the Civic Public: Some Implications of Feminist Critiques of Moral and Political Theory, in FEMINISM, THE PUBlic AND THE PRIVATE 421 (Joan B. Landes ed., 1998) (discussing the ways in which privacy rhetoric excludes particular persons and ideas from public discussion).

10. See FinemAN, The AuTONOMY MYTH, supra note 2, at 59, 208.

11. Id. at 223-25.

12. See Saskia Sassen, Losing Control? Sovereignty in an AgE of Globalization 9-10 (1996) (arguing that globalization has resulted in the partial erosion of the nation-state); see generally Robert O. Keohane, After Hegemony: CoOperation and Discord in the World Political 
effect of globalization has been the displacement of the state by multinational corporations. ${ }^{13}$ Trade arrangements and treaties that span traditional geographic boundaries are agued to have rendered the state relatively impotent.

I propose a different interpretation. The state is not withering away. Rather, it has withdrawn or been prevented by entrenched interests from fulfilling one of its traditional roles in the social compact: to act as the principal monitor or guarantor of an equal society. The fact that nonintervention has facilitated a skewed and unequal society with the distance between rich and poor growing in recent years, makes clear that some form of prevailing power is essential to counter unfettered self-interest. Understood historically as the manifestation of public authority and the ultimate legitimate repository of coercive power, the state is the only realistic contender in that regard. ${ }^{14}$ One pressing issue for those interested in furthering a new vision of equality must be how to modernize or refine this conception of the state and then explicitly define its appropriate relationship to institutions and individuals within contemporary society.

A first step in this reconception is understanding that the state itself is manifested through complex institutional arrangements. Through the exercise of legitimate force in bringing societal institutions into legal existence and subsequently regulating them under its mandate of its public authority, the state also constitutes itself. ${ }^{15}$ For example, although we often experience entities such as the family and the corporation as "natural" or inevitable in form and function, in reality such institutions are constructed and evolving; their identities are legitimated in law, hence by the state. Both intimate and economic entities are creatures of the state, in the sense that they are brought into legal existence by the mechanisms of the state. The state determines how both family and corporation, for example, are created as coherent entities entitled to act as such in society.

This process of institutional creation also establishes the state as the ultimate source of public authority. Its law tells us who may join together by structuring what will constitute a legitimate institutional formation and determines the consequences of that union, be it marital or corporate in form. Law defines the circumstances under which an entity and its actions will be considered entitled to the special protection of law. Once the legal union is

ECONOMY (2d. ed. 2005) (discussing the growth of international trade regimes and neoliberal institutions and the decline of the traditional realist model of nation-state politics).

13. SASSEN, supra note 12 , at 8.

14. The "state" referred to in this analysis is not necessarily the nation-state. The term is used to refer to an organized and official set of linked institutions that together hold coercive power, including the ability to make and enforce mandatory legal rules, and that is legitimated by claim to public authority. In form the "state" could be locally, nationally, transnationally, or internationally organized.

15. See generally JOAN WALLACH SCOTT, GENDER AND THE POLITICS OF HISTORY 48-49 (1999) (discussing the ways in which state authority is continually reconstituted and reaffirmed by actions taken in the name of protecting the public and how these actions depend upon a series of gendered exclusions). 
established, the state may also insist on participating in its termination and can dictate the terms under which separation or dissolution may occur.

Many economists would respond to such observations with the assertion that the structuring of institutions can be, and increasingly is, handled through private ordering-through contract. ${ }^{16}$ However, contracts have no independent force; they are merely documents dependent on the institutions of the state to give them life through interpretation, implementation and execution. No matter how we try to isolate transactions, the state is always a residual player in socalled private arrangements, having fashioned both the background rules that shape those agreements and maintaining the background institutions upon which parties ultimately rely. The state, in exercising its unique role as the creator of legitimate social organizations susceptible to its ongoing coercive authority, should assume a corresponding responsibility to see that these organizations operate in an equitable manner.

Given the state of non-interventionist rhetoric, a brief digression on the issue of state competence is warranted. Critics of an active state often argue that state bureaucracies are inefficient and potentially corrupt. ${ }^{17}$ Because of the escalating sense of both the inevitability and the superiority of privatization within American political culture, we now live in an era of private schools, private prisons, even a private military-a world in which corporations perform functions that used to be classified as public in nature, displacing the state and its responsibility in doing so. It is as though the state-the public — cannot add anything distinctive. We just want to get the job done as quickly, quietly, and cheaply as possible, and it is presumed that private entities will be superior to the state in this regard. ${ }^{18}$

These worries about efficiency and corruption need to be addressed in any theory that argues for state action. While corruption can and should be addressed through criminal and regulatory law, we must inquire more thoughtfully into whether or not efficiency is the paramount or only appropriate measure of state success. Should social goods, such as education, or social responsibilities, such as those related to the criminal justice system, be measured only in terms of efficiency? Economic measures may be important, but are they the only bottom-line-the ultimate bottom-line?

16. See Victor $\mathrm{P}$. Goldberg, The Enforcement of Contracts and Private Ordering, in HANDBOOK OF New Institutional ECONOMICS, 491, 491 (Claude Ménard \& Mary M. Shirley eds., 2005) ("The primary purpose of contract law is, most would concede, to facilitate private ordering. The parties are the best judges of their interests and the law should, as much as possible, stay out of the way.").

17. See, e.g., Robert S. Gilmour \& Laura S. Jensen, Reinventing Government Accountability: Public Functions, Privatization, and the Meaning of "State Action," 58 PUB. ADMIN. REV. 247, 247-48 (1998) (documenting the increasing trend toward privatization and critiquing the abdication of state responsibility through inaction).

18. Experience with Halliburton Energy Services in Iraq, for example, may indicate that the private is not always the cheapest. Nor does experience support the notion that private entities are always more efficient or less corrupt than state efforts. 
Should independent and public values that further the public good, such as equality, justice, and fairness, not be measured and considered when we assess the value of public action? How can public goals be articulated and established without considering how they are consistent with public norms? Public values such as equality or justice are largely unquantifiable, which may explain why they are not typically addressed in neo-classical economics, nor often considered an integral part of the normative system that governs the market and other economic institutions. However, because the state is theoretically freed from the market and profit constraints placed on individual industries and businesses, it should be seen as in a superior position to develop expertise and competence in regard to the implications and implementation of public values. Unlike corporations, which are presumed to act only to maximize profits, the state can and does operate to accomplish more ambitious, even if ultimately immeasurable and illusive, goals. Further, if the preservation and implementation of public values are areas of state responsibility, this responsibility should extend to ensuring that to the extent possible, public goods are distributed according to those values as well.

\section{THE VULNERABILITY THESIS}

In discussions of public responsibility, the concept of vulnerability is sometimes used to define groups of fledgling or stigmatized subjects, designated as "populations." 19 Vulnerability is typically associated with victimhood, deprivation, dependency, or pathology. ${ }^{20}$ For example, public health discourse refers to "vulnerable populations," such as those who are infected with HIV-AIDS. ${ }^{21}$ Groups of persons living in poverty or confined in prisons or other state institutions are often labeled as vulnerable populations. Children and the elderly are prototypical examples of more sympathetic vulnerable populations.

In contrast, I want to claim the term "vulnerable" for its potential in describing a universal, inevitable, enduring aspect of the human condition that must be at the heart of our concept of social and state responsibility. Vulnerability thus freed from its limited and negative associations is a powerful

19. See FINEMAN, THE AUTONOMY MYth, supra note 2, at 33-35.

20. See, e.g., Caroline KNowles, Family Boundaries: THE INVEnTION OF NoRmality and DANGEROUSNESS 108-09 (1996) (discussing popular constructions of children, women, and minorities as vulnerable, pathological, and in a perpetual state of victimhood).

21. Public health is a fertile area for analysis of vulnerable populations in this mode. For an interesting example of vulnerable population analysis, see LEIYU SHI \& GREGORY D. STEVENS, VULNERABLE POPULATIONS IN THE UNITED STATES (2005). The authors consider vulnerability in the light of multiple, cumulative risk factors in regard to designated groups within society classified as to racial/ethnic background, low socioeconomic status, and lack of health insurance. See id. at 2 . The designated population approach is not premised on the universality of vulnerability, as I argue, but is limited to specific categories. 
conceptual tool with the potential to define an obligation for the state to ensure a richer and more robust guarantee of equality than is currently afforded under the equal protection model. ${ }^{22}$

This vulnerability approach both expands upon and complements earlier work I have done in theorizing dependency. The technique is to focus on a concept or term in common use, but also grossly under-theorized, and thus ambiguous. Even when the term is laden with negative associations, the ambiguity provides an opportunity to begin to explore and excavate the unarticulated and complex relationships inherent but latent in the term. ${ }^{23}$ Thus reconsidered, the concept of vulnerability can act as a heuristic device, pulling us back to examine hidden assumptions and biases that shaped its original social and cultural meanings. Conceiving of vulnerability in this way renders it valuable in constructing critical perspectives on political and societal institutions, including law. ${ }^{24}$ Vulnerability raises new issues, poses different questions, and opens up new avenues for critical exploration.

Vulnerability initially should be understood as arising from our embodiment, which carries with it the ever-present possibility of harm, injury, and misfortune from mildly adverse to catastrophically devastating events, whether accidental, intentional, or otherwise. Individuals can attempt to lessen the risk or mitigate the impact of such events, but they cannot eliminate their possibility. Understanding vulnerability begins with the realization that many such events are ultimately beyond human control. ${ }^{25}$

Our embodied humanity carries with it the ever-constant possibility of dependency as a result of disease, epidemics, resistant viruses, or other biologically-based catastrophes. Our bodies are also vulnerable to other forces in our physical environment: There is the constant possibility that we can be injured and undone by errant weather systems, such as those that produce flood, drought, famine, and fire. These are "natural" disasters beyond our individual control to prevent. ${ }^{26}$ Our bodily vulnerability is enhanced by the realization that

22. See supra Part I.

23. For the development of the dependency theory, see generally FINEMAN, THE AUTONOMY MYTH, supra note 2.

24. As I have earlier defined the term, dependency is deemed "inevitable" when applied to biological or developmental stages of life, and "derivative" when considering the social arrangements inherent in caretaking. The theoretical insight is that caretakers need resources in order to undertake care for children, the ill, the elderly, and so on, and are thus derivatively dependent. Society is structured in such a way as to make the private family the primary source of those resources, resulting in great inequalities, including that other societal institutions that benefited from carework are free to evade responsibility to accommodate or compensate caretakers in any way. See FINEMAN, THE AUTONOMY MYTH, supra note 2, at 57-70.

25. I understand vulnerability, in its individual universality, to be similar but not identical to inevitable dependency. Whereas both are universal, only vulnerability is constant, while inevitable dependency is episodic, sporadic, and largely developmental in nature.

26. Environmental disasters are not always beyond society's influence: Human actions can exacerbate environmental threats, as we see with global warming, water pollution, and war. Humaninduced environmental catastrophes, as well as institutional failures more generally, raise additional questions about the ability of institutions to mitigate vulnerability. 
should we succumb to illness or injury there may be accompanying economic and institutional harms as a result of disruption of existing relationships.

Because we are positioned differently within a web of economic and institutional relationships, our vulnerabilities range in magnitude and potential at the individual level. Undeniably universal, human vulnerability is also particular: it is experienced uniquely by each of us and this experience is greatly influenced by the quality and quantity of resources we possess or can command. ${ }^{27}$ Significantly, the realization that no individual can avoid vulnerability entirely spurs us to look to societal institutions for assistance. Of course, society cannot eradicate our vulnerability either. However, society can and does mediate, compensate, and lessen our vulnerability through programs, institutions, and structures. Therefore, because both our personal and our social lives are marked and shaped by vulnerability, a vulnerability analysis must have both individual and institutional components.

\section{A. The Vulnerable Subject}

Understanding the significance, universality, and constancy of vulnerability mandates that politics, ethics, and law be fashioned around a complete, comprehensive vision of the human experience if they are to meet the needs of real-life subjects. Currently, dominant political and legal theories are built around a universal human subject defined in the liberal tradition. ${ }^{28}$ These theories presume the liberal subject is a competent social actor capable of playing multiple and concurrent societal roles: the employee, the employer, the spouse, the parent, the consumer, the manufacturer, the citizen, the taxpayer, and so on. This liberal subject informs our economic, legal, and political principles. It is indispensable to the prevailing ideologies of autonomy, self-sufficiency, and personal responsibility, through which society is conceived as constituted by self-interested individuals with the capacity to manipulate and manage their independently acquired and overlapping resources. $^{29}$

The legal metaphor encapsulating this vision of societal organization is "contract." Liberal subjects have the ability to negotiate contract terms, assessing their options and making rational choices. They consent to such agreements in the course of fulfilling society's mandate that they assume personal responsibility for themselves and for their dependants. Privacy principles that restrain the state and its institutions from interfering with the

27. Vulnerability is like derivative dependency in that it is profoundly shaped by social institutions. However, while only some individuals in society are derivatively dependent as a result of the care work they are assigned or assume, everyone is vulnerable. So, while vulnerability is both inevitable and universal, it is also socially constructed in its particularities.

28. FINEMAN, THE AUTONOMY MYTH, supra note 2, at 18-20.

29. For my critique of the liberal subject, see $i d$. at 224-27. 
liberal subjects' entitlements to autonomy and liberty depend on this presumed competence and capability.

Vulnerability analysis questions the idea of a liberal subject, suggesting that the vulnerable subject is a more accurate and complete universal figure to place at the heart of social policy. There have been many critiques of the liberal subject, most of which focus on autonomy. For instance, feminist scholars have scrutinized and criticized the ways in which dominant theory and popular politics idealize notions of independence, autonomy, and self-sufficiency that are empirically unrealistic and unrealizable. Feminist critics, specifically in bringing dependency and care work into light and under scrutiny, have offered a model of interdependence in which the liberal subject is enmeshed in a web of relationships and perceived as dependent upon them. ${ }^{30}$

A vulnerability critique builds on these insights, but differs in several ways. Vulnerability is a more encompassing concept and, for that reason, analyses centered around vulnerability are more politically potent than those based on dependency. Because dependency is episodic and shifts in degree on an individual level for most of us, mainstream political and social theorists can and often do conveniently ignore it. In their hands, dependency, if acknowledged at all, is merely a stage that the liberal subject has long ago transcended or left behind and is, therefore, of no pressing theoretical interest. In addition, society has historically dealt with dependency by relegating the burden of caretaking to the family, which is located within a zone of privacy, beyond the scope of state concern absent extraordinary family failures, such as abuse or neglect. Thus largely rendered invisible within the family, dependency is comfortably and mistakenly assumed to be adequately managed for the vast majority of people.

By contrast, understood as a state of constant possibility of harm, vulnerability cannot be hidden. Further, while institutions such as the family may provide some shelter, they are unable to eliminate individual vulnerability and are themselves vulnerable structures susceptible to harm and change. Because vulnerability is ever-present and enduring, institutional as well as individual, it suggests a critique of dominant modes of thinking about inequality that is at once complementary to but more powerful than dependency. My argument is not for vulnerability to supplant dependency, for they each reveal different and important things. Rather, the assertion is that vulnerability analysis may ultimately prove more theoretically powerful.

In addition, the vulnerability perspective calls attention to another problematic characteristic of the liberal subject: S/he can only be presented as an adult. As such, the liberal subject stands not only outside of the passage of time, but also outside of human experience. The construction of the adult

30. See, e.g., id. at 161-75 (discussing feminist critiques of autonomy and the myriad of ways in which social institutions structure individuals' lives). 
liberal subject captures only one possible developmental stage-the least vulnerable-from among the many possible stages an actual individual might pass through if s/he lives a "normal" lifespan. We must confront this foundational fiaw in the liberal model if we are to develop legal and social policies that reflect the lived realities of human subjects.

The vulnerable subject approach does what the one-dimensional liberal subject approach cannot: it embodies the fact that human reality encompasses a wide range of differing and interdependent abilities over the span of a lifetime. The vulnerability approach recognizes that individuals are anchored at each end of their lives by dependency and the absence of capacity. Of course, between these ends, loss of capacity and dependence may also occur, temporarily for many and permanently for some as a result of disability or illness. Constant and variable throughout life, individual vulnerability encompasses not only damage that has been done in the past and speculative harms of the distant future, but also the possibility of immediate harm. We are beings who live with the everpresent possibility that our needs and circumstances will change. On an individual level, the concept of vulnerability (unlike that of liberal autonomy) captures this present potential for each of us to become dependent based upon our persistent susceptibility to misfortune and catastrophe.

\section{B. The Vulnerable Society and Its Institutions}

The vulnerable subject thus presents the traditional political and legal theorist with a dilemma. What should be the political and legal implications of the fact that we are born, live, and die within a fragile materiality that renders all of us constantly susceptible to destructive external forces and internal disintegration? Bodily needs and the messy dependency they carry cannot be ignored in life, nor should they be absent in our theories about society, politics, and law. Surely the reality of our universal fragility has played some role in our construction of societal institutions. Contemplating our shared vulnerability it becomes apparent that human beings need each other, and that we must structure our institutions in response to this fundamental human reality.

Of course, societal institutions themselves are not foolproof shelters, even in the short term. Metaphorically, they too can be conceptualized as vulnerable: They may fail in the wake of market fluctuations, changing international policies, institutional and political compromises, or human prejudices. Even the most established institutions viewed over time are potentially unstable and susceptible to challenges from both internal and external forces. ${ }^{31}$ Riddled with

31. My conception of vulnerability departs from that of other theorists, such as Judith Butler, who argues for a theory of vulnerability that is preoccupied with the human capacity for loss, death, and tragedy. Butler proposes a framework of grief and suffering as a mechanism of reconsidering the ways in which certain lives become more privileged or valued than others. See JUDITH BUTLER, PRECARIOUS LIFE: THE POWERS OF MOURNING AND VIOLENCE 30 (2004). By examining grief and finding ways to 
their own vulnerabilities, society's institutions cannot eradicate, and often operate to exacerbate, our individual vulnerability. In fact, awareness of these institutional fallibilities may intersect with the specter of our own possible dependency, making reliance on these institutions particularly frightening.

One promising theoretical potential of making vulnerability central in an analysis of equality is that attention to the situation of the vulnerable individual leads us to redirect focus onto the societal institutions that are created in response to individual vulnerability. This institutional focus has the effect of supplementing attention to the individual subject by placing him/her in social context. The institutions of particular interest are those that are created and maintained under the legitimating authority of the state, since the ultimate objective of a vulnerability analysis is to argue that the state must be more responsive to, and responsible for, vulnerability. ${ }^{32}$

The state facilitated institutions that have grown up around vulnerability are interlocking and overlapping, creating the possibility of layered opportunities and support for individuals, but also containing gaps and potential pitfalls. These institutions collectively form systems that play an important role in lessening, ameliorating, and compensating for vulnerability. ${ }^{33}$ Together and independently they provide us with what Peadar Kirby refers to as "assets"advantages, coping mechanisms, or resources that cushion us when we are facing misfortune, disaster, and violence. Cumulatively these assets provide individuals with "resilience" in the face of vulnerability. ${ }^{34}$

In his evaluation of violence and vulnerability, Kirby identifies three different types of assets that social organizations and institutions provide:

grieve, Butler argues that we "might critically evaluate and oppose the conditions under which certain human lives are more vulnerable than others, and thus certain human lives are more grievable than others." Id. However, Butler's theory stops short of calling for restructuring our institutions in ways that reflect our vulnerability. Because institutions are simultaneously constituted by and producers of vulnerability, we must continually challenge these institutional practices and the meting of social resources. Thus, where Butler remains suspicious of "governmentality" and the ways in which the state intervenes to protect the population, my theory of vulnerability requires an active engagement with these institutions precisely because they are vulnerable and receptive to demands. For example, Butler does not challenge the ways in which the formal equality model and anti-discrimination framework perpetuate inequality and mask vulnerability under the guise of autonomy. See id. at 25-26.

32. These institutions in combination with the legal and governmental structures that bring them into existence and monitor their activities constitute the state as I conceive of it. See supra p. 6.

33. See BRYAN S. TURNER, VULNERABILITY AND HUMAN RIGHTS 25-44 (2006). Turner recognizes the importance of a vulnerability analysis in the development of international institutions that are receptive to human needs. However, Turner's theory of vulnerability focuses on the ways in which human rights abuses create vulnerability and prevent institutions from effectively protecting the population.

34. This discussion on systems addressing vulnerability builds on PEADAR KIRBY, VULNERABILITY AND VIOLENCE (2006). In discussing resilience, Kirby builds on earlier definitions that understood resilience as "enabling units such as individuals, households, communities and nations to withstand internal and external shocks." Id. at 55 (quoting the United Nations Economic Commission for Latin American and the Caribbean). 
physical assets, human assets, and social assets. ${ }^{35}$ Institutions that provide us with physical assets are those that impart physical or material goods through the distribution of wealth and property. These assets determine our present quality of life, and provide the material basis for accumulation of additional resources-or resources that are more sustainable-in the form of savings and investments. ${ }^{36}$ Certainly tax and inheritance laws impact the distribution of physical assets and are part of this system, but so also are banking rules and regulations, and credit policies. ${ }^{37}$

Like physical assets, human assets also affect material well-being. Defined as "innate or developed abilities to make the most of a given situation,", 38 human assets provide on an individual level for the accumulation of human capital or "capabilities." 39 Kirby identifies health and education as chief among assets in this category, making the institutions governing education and health care prime candidates for a vulnerability analysis. ${ }^{40}$ In addition to the examples Kirby provides, employment systems should be added; like education and healthcare, they develop the human being, impart assets that allow participation in the market and, thus, facilitate the accumulation of material resources that help bolster individuals' resilience in the face of vulnerability.

35. Id. at 55. Kirby identifies a fourth category: environmental assets. He notes that this set of assets is often overlooked due to the prevalence of economic analysis, which in its neoclassic form gives "priority to monetary value and which, by and large, treats environmental assets as 'externalities." I $I$. at 69. Systems and institutions falling into this category include those addressing issues of global warming, bio-diversity, wildlife, and natural resources that affect individuals and societies worldwide. Id. At 6972.

36. Id. at 54-55.

37. Kirby notes that residential property is the single biggest asset class, accounting for forty to sixty percent of total household wealth in Europe and around 30 percent in the United States. He warns that a crisis in the housing market could be worse than a depression, a warning that seems prescient in view of the recent world-wide crisis generated by the sub-prime debacle. $I d$. at 59 .

38. Id. at 60. This aspect of Kirby's work reflects some dimensions of Amartya Sen's analyses. He notes that Sen does not address vulnerability, but emphasizes capabilities and what constitutes "wellbeing" in a way that "highlights important dimensions of what we can call the social production of resilience." Id. at 55. I believe Kirby's multiple asset-conferring institutional analysis is richer and more helpful in articulating a basis for state responsibility than is the Sen focus on the development of individual capabilities. In setting out a system approach in which a variety of structures confer different, complementary types of assets, Kirby is reaching for robust categories that capture the complex dimensions of the idea of resilience. $I d$.

39. Martha Nussbaum has argued that social justice is best achieved through a "capabilities" based approach. See, Martha C. Nussbaum, Frontiers of Justice: Disability, Nationality, SPECIES MEMBERSHIP 70, 164 (2006). Nussbaum argues that situations of substantial dependence, for example that of a person in a vegetative state or a person who is permanently confined to a wheelchair, result in certain individuals requiring more resources than others. Id. at 164-65. The capabilities approach attempts to define a minimum level of human capability "in a way informed by an intuitive idea of a life that is worthy of the dignity of the human being." Id. at 70 . By focusing on the base level of human worth and defining the components of that life, Nussbaum's theory perpetuates social inequality in potentially dangerous ways. Enabling society or even individuals to define what does and does not constitute a valuable life echoes with arguments historically resulting in eugenics, discrimination, and social inequality. As such, Nussbaum's theory of dependency and human capabilities fails to capture the benefits of a vulnerability approach that challenges social inequalities while maintaining an ethic of universal applicability.

40. KIRBY, supra note 38, at 60 . 
Finally, social assets are networks of relationships from which we gain support and strength, including the family and other cultural groupings and associations. Kirby argues persuasively that social assets are also accumulated through political collectives in which individuals bolster their resilience by joining together to address vulnerabilities generated by the market. ${ }^{41}$ These collectives historically included trade unions and political parties, but todayas Kirby recognizes - the welfare state and insurance are also offered as alternative, often competing, means of protection against risk.

Kirby's description of assets and asset-conferring institutions is analytically helpful in constructing a vulnerability analysis in that it illuminates the link between asset accumulation by individuals and the creation and maintenance of societal institutions. The nature of this relationship, coupled with the fact that asset conferring institutions initially are brought into legal existence only through state mechanisms, places such institutions within the domain of state responsibility. As asset-conferring entities, these institutions distribute significant societal goods and should be more specifically regulated; normatively, this state involvement requires that the state be vigilant in ensuring that the distribution of such assets is equitable and fair. Together with the concept of the vulnerable subject, understanding the state's relationship to asset-conferring institutions gives us a vocabulary for arguing that the state should be held accountable for ensuring equality in response to individual and institutional vulnerability. ${ }^{42}$

\section{ASSESSING AND ADDRESSING PRIVILEGE AND DisADVANTAGE}

Within the various systems for conferring assets, individuals are often positioned differently from one another, so that some are more privileged, while others are relatively disadvantaged. Important to the consideration of privilege is the fact that these systems interact in ways that further affect these inequalities. Privileges and disadvantages accumulate across systems and can combine to create effects that are more devastating or more beneficial than the weight of each separate part. Sometimes privileges conferred within certain systems can mediate or even cancel out disadvantages conferred in others. A

41. Id. at $64-69$.

42. It would be interesting in future work to broaden the idea of asset categories. Perhaps distinctions between asset-conferring, asset-preserving, and asset-enhancing systems would be helpful. Also relevant to the idea of resilience, and for that reason eminently worthy of study, are those institutions that do not confer individual assets per se, but provide some collective social good, such as maintaining order. In this category would be the criminal justice system and the armed services. Of further interest are the systems designed with institutions, not individuals, as the primary regulatory objects. Such systems guide capital and nation states in accumulation and consolidation, and determine the range and viability of international interactions and relations. I would place international treaties and United Nations conventions in this system, since they are directed toward the governance of collective entities. Individuals might be benefited through such systems, but they are not perceived as their primary objective. 
good early education may triumph poverty, particularly when coupled with a supportive family and progressive social network.

Therefore, with respect to the assets any one person possesses, it is not multiple identities that intersect to produce compounded inequalities, as has been posited by some theorists, but rather systems of power and privilege that interact to produce webs of advantages and disadvantages. ${ }^{43}$ Thus, where other theorists expand the traditional equal protection analysis to account for multiple intersecting identities, ${ }^{44}$ a vulnerability analysis provides a means of interrogating the institutional practices that produce the identities and inequalities in the first place.

Using this systematic approach, a vulnerability analysis can address some of the ambiguities and anomalies that are evident in our current models of discrimination and in the identity categories these models utilize. Focusing on the interactions of asset-conferring institutions makes clear why some individuals can maneuver past disadvantages typically associated with our existing discrimination categories of race or gender to excel, even triumph, in a "white man's world." The various systems and institutions these individuals have encountered have provided them with the accumulated assets they needed to succeed. Such successes sometimes result in rejection of group identification and denial of group-associated disadvantages and measures designed to address them both by society in general and by successful individuals themselves. There are women CEOs who reject the idea that accommodations should be made for caretakers of small children or aging parents; wealthy and successful African Americans who launch campaigns against affirmative action in college admissions; and Latinos who are as adamant that we ferret out and deport undocumented workers as are their white counterparts.

These individuals do not disprove the existence of structural inequalities or the need for remedial action, however. Rather, they should be seen as the beneficiaries of institutions and systems in which privileges are conferred in more complex and particular ways than a simplistic focus on identity and discrimination would allow. Privileged within intersecting systems, these individuals have escaped both materially and psychologically from what are often cast as the inevitable disadvantages conferred by their gender, race, or ethnicity. Their successes lessen their identification with unmodified categories like race or gender and sometimes even make them opponents of the very policies that assisted them.

43. See, e.g., Angela P. Harris, Race and Essentialism in Feminist Legal Theory, 42 STAN. L. REV. 581,587 (1990) ("Feminists have adopted the notion of multiple consciousness as appropriate to describe a world in which people are not oppressed only or primarily on the basis of gender, but on the bases of race, class, sexual orientation, and other categories in inextricable webs."); see also id. At 588$89,598,601$ (critiquing gender essentialism).

44. See Judy Scales-Trent, Black Women and the Constitution: Finding Our Place, Asserting Our Rights, 24 HARV. C.R.-C.L. L. REv. 9 (1989) (focusing on the intersections of race and gender for black women in light of the various standards of review under the Equal Protection Clause). 
Just as privilege is not tethered to identity neither is disadvantage. Vulnerability is universal and, as such, transcends historic categories of impermissible discrimination. The sub-prime mortgage crisis affected white and middle-class people as well as those in the traditional suspect categories. Welfare reform during the 1990s should have been understood as a direct attack on all caretakers in that it undermined the value of unpaid care work and demonized motherhood outside of the patriarchal paradigm. ${ }^{45}$

The realization that disadvantage is produced independent of racial and gender biases in many-but of course not all-instances provides an important political tool. Mobilizing around the concept of shared, inevitable vulnerability may allow us to more easily build coalitions among those who have not benefited as fully as others from current societal organization. If we begin to operate from this perspective, institutional arrangements will be the targets of protest and political mobilization, and interest groups need not be organized around differing identities. The justice inquiry will also be reconfigured: It will focus on whether existing institutional arrangements are equally attentive across individuals and groups with shared vulnerability and assets are conferred in an equitable manner, or conversely if some subset is unduly privileged.

Of course, discrimination along identity lines unfortunately is likely to continue to occur; and, if it does, there will be an ongoing need to protest and remedy such discrimination. But, relative to relying on equal protection analysis, focusing on shared vulnerabilities and building a political movement around unequal institutional arrangements attendant to those vulnerabilities is a far more promising and powerful approach in addressing and correcting the disadvantage that persists in society. As noted earlier, discrimination-based arguments have accomplished too little with respect to dismantling broad systems of disadvantage that transcend racial and gender lines, such as poverty. ${ }^{46}$ Our understanding of equality has been so constrained by prevailing discrimination models that any radical potential of identity-based politics that may have once existed is now perhaps beyond resuscitation. The vulnerability approach will take us further, for despite progressive attempts to build strong and enduring coalitions across identity groups, such a coalition has not by and large emerged.

A vulnerability approach accomplishes several other important political objectives that illuminate both why a post-identity paradigm is necessary and how powerful it can be in addressing existing material and social inequalities. First, it allows us to celebrate the progress toward racial, ethnic, and gender equality that has been made under the anti-discrimination model. Institutions

45. See Martha Albertson fineman, The Neutered Mother, The Sexual Family, and OTHER TWENTIETH CENTURY TRAGEDIES 101-10 (1995) (discussing mothers of all races characterized as deviant for their rejection of the patriarchal form of family).

46. See supra notes 4-7 and accompanying text. 
that were historically closed to women, African Americans, and other nonwhite males are now formally open, and many individuals have flourished as a result. Yet many are left behind, including some white males. Current antidiscrimination law and formal equality provide little in terms of rectifying many of the disadvantages these people face. Institutional exclusion in the formal, historic sense is not the reason that these individuals are not flourishing. ${ }^{47}$

Some politicians and policy makers have suggested that those left behind are merely suffering the just results of their own individual failures and inadequacies. ${ }^{48}$ These assertions rely on the assumption that unsuccessful persons have simply not demonstrated individual responsibility by taking advantage of the equally available opportunities afforded to them under existing societal systems. But the claim of failure of personal responsibility might be harder to make if we do not frame equality arguments in terms of the absence of impermissible discrimination but, rather, question whether the system provided an impermissible advantage to some individuals or groups. Within that framework, claims that individuals are entirely responsible for their own failures become less tenable. A vulnerability inquiry proposes a more thorough and penetrating equality analysis-one that considers structural and institutional arrangements in assessing the state's response to situations of vulnerability before indicting the individual.

This structural focus illustrates a second political advantage to a vulnerability analysis: It brings institutions-not only individual actionsunder scrutiny, redirecting our attention to their role in providing assets in ways that may unfairly privilege certain persons or groups, even if unintentionally. Remember that institutions as well as individuals are vulnerable to both internal and external forces. They can be captured and corrupted. They can be damaged and outgrown. They can be compromised by legacies of practices, patterns of behavior, and entrenched interests that were formed during periods of exclusion and discrimination, but are now invisible in a haze of lost history. Nonetheless, these institutions also have a vital role to play in addressing individual vulnerability. The resources they provide are the assets that allow us to live and aspire toward happiness despite our vulnerability. It is important that they operate in a non-discriminatory manner and neither favor nor disadvantage certain individuals or groups. Intent is irrelevant, what matters is whether or not these institutions are structured so as to respond unequally to the reality of our shared vulnerability. If they are, the burden would be on the state to either

47. Affirmative action plans are premised on the anti-discrimination model. They are perceived as temporary adjustments to the formal equality paradigm necessitated by past discrimination. Since they are based on historic individual identity categories, they do not focus us on institutions, which is where we need to direct our attention if we are to address the more complicated forms of disadvantage we face in a post-equality society.

48. See Fineman, The Autonomy MYth, supra note 2, at 34. 
justify that inequality or act to adjust the institutional arrangements. This type of coercive institutional supervision can only be undertaken by the state in its capacity as the legitimate manifestation of public authority.

\section{THE RESPONSIVE STATE}

Replacing the liberal subject with a vulnerable subject, and articulating a corresponding and compelling argument for fashioning a state more responsive to that subject, is not an easy task. Critics may argue that attacks on the liberal subject destabilize liberalism itself: If a competent, responsible adult is not at the center of social and political theory, will this not inevitably lead to less democratic modes of government and a more authoritarian state? The answer to such questions, which are anchored in an attachment to the status quo, should begin with some consideration of the history and development of our democracy and its institutions. Our current system has been built upon myths of autonomy and independence and thus fails to reflect the vulnerable as well as dependent nature of the human condition. This theoretical weakness has had practical implications that undermine our aspirations for equality and democracy.

In addition, we must think beyond current ideological constraints and consider the possibility of an active state in non-authoritarian terms. This theoretical task-reconceptualizing the role of the state-requires that we imagine responsive structures whereby state involvement actually empowers a vulnerable subject. Certainly state mechanisms that ensure a more equitable distribution of assets and privilege across society would contribute to a more robust democracy and greater public participation. The choice, then, is not one of an active versus inactive state per se, but rather whether the state is constructed around a well-defined responsibility to implement a comprehensive and just equality regime.

As stated earlier in this Essay, our present conceptions of the state underestimate or even ignore the many ways in which the state--through lawshapes institutions from their inception to their dissolution. ${ }^{49}$ Currently, the state minimally supervises these institutions in fulfilling their essential role in providing the assets that give us resilience in the face of vulnerability. The mandate of equal protection under statutes and the Constitution prohibits discrimination and, absent the demonstration of compelling differences and/or state interest, equality of treatment is the legal norm. However, by relying on the myth of the autonomous individual, the formal equality model fails to address substantive inequalities and differential allocations of privilege produced by our institutions. ${ }^{50}$ Instead, by focusing on equal protection and

49. See supra pp. 6-7.

50. See supra Part I. 
formal equality, the current model mires us in a battle of identity politics where every gain by a minority individual becomes a justification for abandoning the pursuit of substantive equality. Moreover, when one person or group gains, other individuals and groups often perceive themselves as losing. This paradigm pits some against others in a negative manner, deflecting sustained attention away from the institutional arrangements and systems that distribute disadvantage across people and groups.

Under both the vulnerability and nondiscrimination approaches the mandate is the same - the establishment of a regime of equality - but the foci and indeed the manner in which equality is imagined are very different. A vulnerability analysis greatly magnifies state responsibility for the institutions and structures the state constructs and utilizes. Vulnerability analysis demands that the state give equal regard to the shared vulnerability of all individuals, transcending the old identity categories as a limitation on the recognition that the state has a vital role to play in protecting against discrimination. A vulnerability analysis begins by first considering how the state has responded to, shaped, enabled, or curtailed its institutions. Has it acted toward those institutions in ways that are consistent with its obligation to support the implementation and maintenance of a vital and robust equality regime-a regime in which individuals have a true opportunity to develop the range of assets they need to give them resilience in the face of their vulnerabilities?

This inquiry into institutional and structural advantages and disadvantages would require a substantial reorientation of political culture, as well as some adjustments to legal institutions and theory. The legislature and its actions would become the primary institutional manifestation of the state. Its mandate would be to be responsive to vulnerability, which would result in a more nuanced sense of what constitutes equal opportunity than currently theorizedone that is more sensitive to existing inequalities and more demanding of the state. This imperative would be placed on the legislature and executive in the first instance: the mandate to be more responsive to and reflective of vulnerability. The legislative and executive fulfillment of that imperative ultimately would be monitored or supervised by the courts, looking to see if the state fulfilled its responsibility in assessing individual equality claims.

The questions a vulnerability analysis poses for equality are not restricted to a focus on discrimination against certain individuals or groups. ${ }^{51}$ Rather the state is required to ensure that institutions and structures within its control do not inappropriately benefit or disadvantage certain members of society. The operation and impact of those institutions and structures become the focus of legislative and executive action. The vulnerability inquiry examines the ways in which societal resources are channeled to see if the result is to privilege and

51. This also helps to problematize the claim that because some members of a group succeed, the system is functioning appropriately and need not be monitored or transformed. 
protect some while tolerating the disadvantage and vulnerability of others. This focus on the structuring of societal institutions reflects the fact that the state has an affirmative obligation not to privilege any group of citizens over others and to actively structure conditions for equality. Imagine how much more fruitfully political and policy discussions might proceed if this framework were the one by which legislative and executive actions were gauged. ${ }^{52}$

A focus on the state and its institutions, as well as privilege and disadvantage, would also change the nature of the legal inquiry presented for judicial determination. It would move courts away from assessing the individual characteristics of designated groups within society to see if they are the subjects of animus. The vulnerability paradigm calls on courts to look beyond the identity of the disadvantaged developed over the past few decades under a discrimination paradigm. While the old identity categories-gender, race, sexuality, and so on-should not be totally removed from consideration, we must reframe our concerns in order to reveal and address things about the organization of society that are otherwise missed.

Similarly, under this approach, the task is not to explore the intent behind the actions of individual employees, educators, landlords, and so on. Individual intention is not the issue, nor is discrimination. Ill will is irrelevant when all of society is operating with the same set of prejudicial assumptions and beliefs such that our culture ignores the many ways it is organized to privilege some and not others. Because the shared, universal nature of vulnerability draws the whole of society-not just a defined minority-under scrutiny, the vulnerability approach might be deemed a "post-identity" analysis of what sort of protection society owes its members.

By recognizing that privilege and disadvantage migrate across identity categories, we are forced to focus not only on individuals, but also on institutions - the structures and arrangements that can almost invisibly produce or exacerbate existing inequality. ${ }^{53} \mathrm{~A}$ vulnerability approach does not mean that

52. A fundamental question about our current societal arrangements that might spark controversy would begin with a consideration of why we organize work and wealth the way we do. I would like to see a discussion in state legislatures and Congress asking such questions about the workings of the law itself as: Why do we privilege contract over status, market over family or individual? Why does law divide up the market analytically and put its various parts in competition with each other: corporation versus workers versus consumers versus government? Why aren't all corporation constituencies represented in corporate governance, and why are only shareholders viewed as stakeholders? Why do we accept the idea of a minimum wage, but view as incomprehensible the idea that there might be a maximum wage under law? Why do we have a fictitious public-private divide imposed on the family and in employment? Lawmakers in other countries ask such questions and respond to them in their policy-making.

At a minimum the vulnerability approach would be premised on the idea that it is inappropriate for the state and its institutions to protect and privilege some, to shield them or to mediate their vulnerability through the creation and maintenance of societal institutions, and it would force us to uncover the ways the state allows some to struggle with vulnerability and dependency.

53. The concept of vulnerability also allows us to avoid the argument based in the theme of individual responsibility that there is no longer any problem in the United States since certain individuals from protected identity groups have experienced successes. 
different treatment, even the conferral of privilege or advantage, is never warranted. It means that if the state confers privilege or advantage, there is an affirmative obligation for it to either justify the disparate circumstances or remedy them. ${ }^{54}$ This would then be the political and legal culture of equality in which the state and our societal institutions and their actions were judged.

\section{A MORE POSITIVE EQUALITY}

Interestingly, the same-sex marriage debates reveal a concrete contemporary application of an approach that is not based on the idea of discrimination against some group, but instead eschews state action that privileges a few while leaving others outside of its protective structure. In some cases, plaintiffs have focused their arguments on the privileges associated with marriage that were denied to same-sex couples. Those benefits are "assets" in a vulnerability thesis-material and relational advantages that arose from or were conferred by the way that the institution of marriage has been structured.

In 1999, the Supreme Court of Vermont looked into its own early American history and held that same-sex couples were entitled to receive the legal benefits and protections that were previously only afforded to married couples of opposite sexes. ${ }^{55}$ The court's rationale in extending these benefits (or assets) to same-sex couples derived, not from arguments of formal equality under the Equal Protection Clause, but from a more expansive and earlier notion of equality derived from the experience of colonial America. ${ }^{56}$ The Vermont Constitution's Common Benefits Clause predated the Fourteenth Amendment and was not based on a concept of discrimination, ${ }^{57}$ nor was it focused only on protection for a specific category of persons. The Common Benefits Clause states, in part, "[t]hat government is, or ought to be, instituted for the common benefit, protection, and security of the people, nation, or community, and not for the particular emolument or advantage of any single person, family, or set of persons, who are a part only of that community . ..."58

The court distinguished federal jurisprudence from its interpretation of Vermont's Common Benefits Clause, which it characterized as concerned with ends rather than merely means. It noted that federal courts had been "broadly deferential to the legislative prerogative to define and advance governmental ends, while vigorously ensuring that the means chosen bear a just and

54. The current prevailing perspective is that state action of this type is inappropriate. We are a people embedded in a national ideology of individualism that is protective of individual liberty and composed of mandates about individual responsibility, state non-intervention, and negative rights.

55. Baker v. State, 744 A.2d 864 (Vt. 1999).

56. Id. at 876-77.

57. Id. at 877-78.

58. VT. Const. ch. I, art. 7. 
reasonable relation to the governmental objective." ${ }^{, 59}$ By contrast, underpinning the Common Benefits Clause was the notion that "the law uniformly afforded every Vermonter its benefit, protection, and security so that social and political preeminence would reflect differences of capacity, disposition, and virtue, rather than governmental favor and privilege.

Baker v. Vermont's discussion of the Common Benefits Clause is an endfocused analysis. The majority continued, noting that the clause "prohibits not the denial of rights to the oppressed, but rather the conferral of advantages or emoluments upon the privileged." ${ }^{\text {"F1 }}$ Further, the Common Benefits Clause, "at its core ... expressed a vision of government that afforded every Vermonter its benefit and protection and provided no Vermonter particular advantage." ${ }^{, 62}$ The majority in Baker did not limit the potential classes whose interests are protected under the Common Benefits Clause to those groups identified by the U.S. Supreme Court as protected under the Constitution. For, as the Court noted, "the plaintiffs are afforded the common benefits and protections of Article 7, not because they are part of a 'suspect class,' but because they are part of the Vermont community." ${ }^{, 63}$ This fact alone compelled the Court to "police a political process whose product frequently discriminates between citizens in respect to benefits and privileges. ${ }^{, 64}$ Baker employs a creative and positive mode of inquiry in line with the vulnerability approach: It is concerned with whether the state, in fashioning its institutions, acts with equal regard for the shared vulnerability of all its legal subjects.

\section{CONCLUSION}

Equality must escape the boundaries that have been imposed upon it by a jurisprudence of identity and discrimination, and the politics that has grown up around this jurisprudence. The promise of equality must not be conditioned upon belonging to any identity category, nor should it be confined to only certain spaces and institutions, be they deemed public or private. Equality must be a universal resource, a radical guarantee that is a benefit for all. We must begin to think of the state's commitment to equality as one rooted in an understanding of vulnerability and dependency, recognizing that autonomy is not a naturally occurring characteristic of the human condition, but a product of social policy.

59. Baker, 744 A.2d at 871 (emphasis omitted).

60. Id. at 876-77.

61. Id. at 874 .

62. Id. at 875 .

63. Id. at $878 \mathrm{n} .10$

64. Lawrence Friedman \& Charles H. Baron, Baker v. State and the Promise of the New Judicial Federalism, 43 B.C. L. REV. 125, 152 (2001). 
